\title{
MRI assessment of cardiomyopathy in Taiwan Chinese late-onset Fabry mutation (IVS4+919G>A)
}

\author{
Yu-Pin Chang ${ }^{*}$, Jyh-wen Chai ${ }^{1}$, Yi-Ying Wu ${ }^{1}$, Yun-Ching Fu², John Wang ${ }^{3}$, Clayton Chi-Chang Chen ${ }^{1}$ \\ From 18th Annual SCMR Scientific Sessions \\ Nice, France. 4-7 February 2015
}

\section{Background}

Fabry disease is a rare $\mathrm{X}$-linked disorder characterized by deficiency of $\alpha$-galactosidase A, leading to progressive accumulation of glycosphingolipid in various organs, including the heart. Recently, several later-onset phenotypes of Fabry disease with residual enzyme activity have been identified. In Taiwan, several recent studies pointed out a surprisingly high incidence of a later onset Fabry mutation (IVS4+919G $>$ A) and there is a lack of information about its cardiac MR appearance in the literature. We aim to present the cardiac MR appearances of this subtype of Fabry disease and compare them with the classic type.

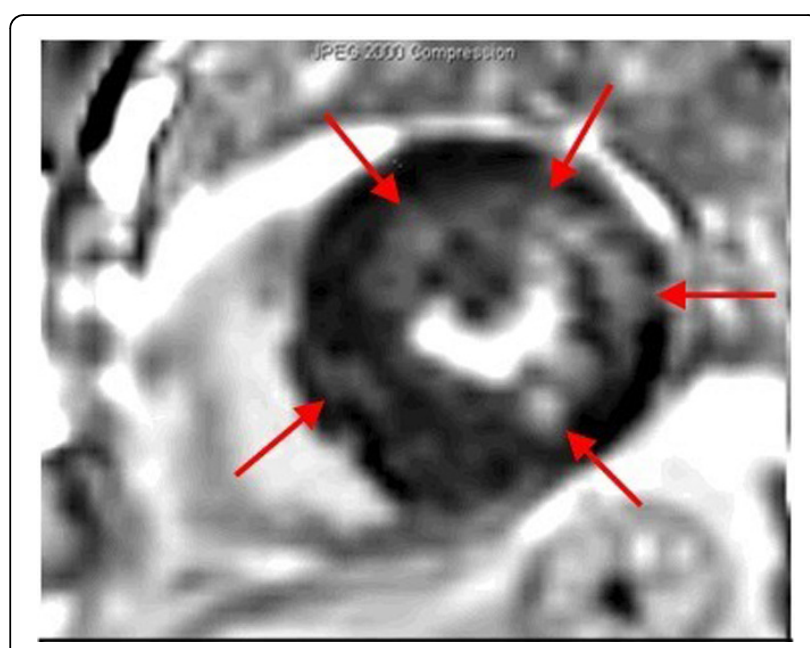

Figure 1 A 68 y/o male with Fabry variant demonstrates delayed myocardial enhancement and wall thickening $(>16 \mathrm{~mm})$ in multiple LV segment, including segment 7,8, 10, 11 and 12 (red arrows). (Other segments were also involved, but not shown in this image.)

${ }^{1}$ Radiology, Taichung Veterans General Hospital, Taichung, Taiwan Full list of author information is available at the end of the article

\section{Methods}

A total of 12 patients ( 9 males and 3 females) were enrolled in this study. They underwent endomyocardial biopsy as well as MR study from July 2013 to September 2014 and were proved to be Fabry mutation (IVS4 $+919 \mathrm{G}>\mathrm{A}$ ). We recorded the location of delayed myocardial enhancement according to modified AHA 16-segment model and measured left ventricular (LV) wall thickness of each segment in short axis view at the end diastole. We categorized these patients into three groups (Group I, II, III) according to their myocardial thickness(all segments $<12 \mathrm{~mm}$, at least one segment $12 \sim 16 \mathrm{~mm}$, at least one segment $>16 \mathrm{~mm}$, respectively ). Among the all

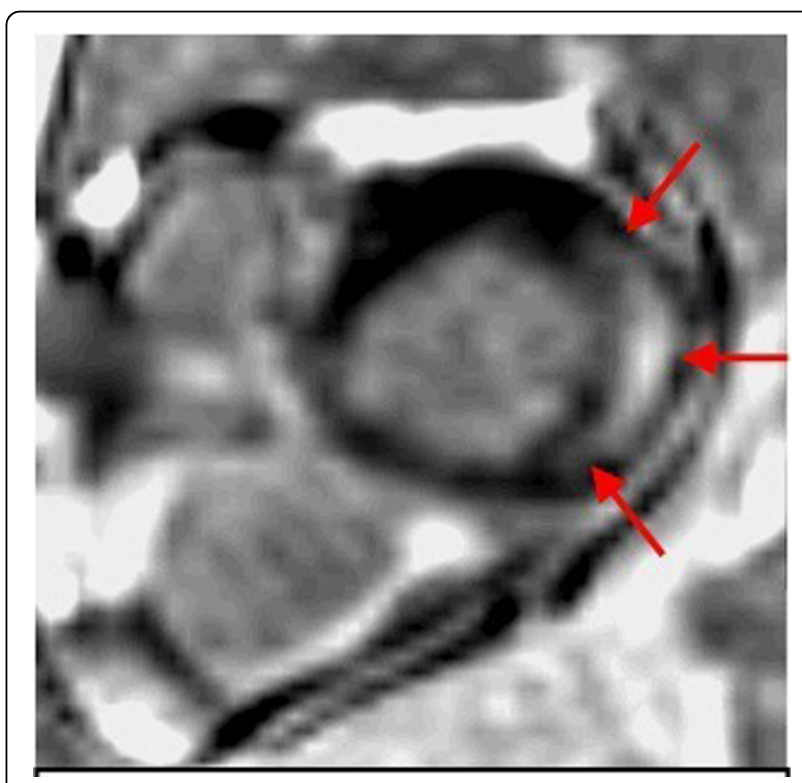

Figure 2 A 55 y/o male with Fabry variant shows delayed myocardial enhancement in LV segment 10, 11 and 12 (red arrows). These segments were only 12 13mm in thickness. 
patients, we used $\mathrm{X}$ square test to evaluate if there was significant difference in presence of delayed enhancement according to different myocardial wall thickness.

\section{Results}

There were 12 patients with 192 myocardial segments (male: 144 segments, female: 48 segments) under evaluation. There were 4 patients in Group III with 22 segments $>16 \mathrm{~mm}, 4$ patients in Group II with 5 segments in range of $13 \sim 16 \mathrm{~mm}$. The remained 4 patients were in Group I. in Group III were. In Group III, there were 15 segments $>16 \mathrm{~mm}$ involving the septum and 13 segments in range of $13 \sim 16 \mathrm{~mm}$. Besides, there were 37 segments with delayed enhancement in Group III, with 14 in posteriolateral wall, 13 in anterior wall and 10 involving the septum. In group I and II, two patients with 4 segments demonstrated delayed enhancement and the 4 segments (segment $4,10,6,11)$ are all in the normal range of thickness $(<12 \mathrm{~mm})$. In the $\mathrm{X}$ square test evaluation, there was significant difference in presence of delayed enhancement dependent on various myocardial wall thickness $(\mathrm{P}<0.05)$.

\section{Conclusions}

In our study, patients with Fabry variant demonstrated some different patterns of delayed myocardial enhancement and wall thickness in cardiac MR as compared with classic Fabry disease.

\section{Authors' details}

${ }^{1}$ Radiology, Taichung Veterans General Hospital, Taichung, Taiwan.

${ }^{2}$ Pediatrics, Taichung Veterans General Hospital, Taichung, Taiwan.

${ }^{3}$ Pathology, Taichung Veterans General Hospital, Taichung, Taiwan.

Published: 3 February 2015

doi:10.1186/1532-429X-17-S1-P276

Cite this article as: Chang et al:: MRI assessment of cardiomyopathy in

Taiwan Chinese late-onset Fabry mutation (IVS4+919G>A). Journal of

Cardiovascular Magnetic Resonance 2015 17(Suppl 1):P276.

\section{Submit your next manuscript to BioMed Central} and take full advantage of:

- Convenient online submission

- Thorough peer review

- No space constraints or color figure charges

- Immediate publication on acceptance

- Inclusion in PubMed, CAS, Scopus and Google Scholar

- Research which is freely available for redistribution

Submit your manuscript at www biomedcentral.com/submit 